\title{
Evidence of oocyte donor cow effect over oocyte production and embryo development in vitro
}

\author{
M. Tamassia ${ }^{1}$, Y. Heyman², Y. Lavergne ${ }^{3}$, C. Richard ${ }^{3}$, V. Gelin ${ }^{3}$, J. P. Renard ${ }^{2}$ \\ and S. Chastant-Maillard ${ }^{1}$ \\ ${ }^{1}$ Ecole Vétérinaire d'Alfort, Biologie de la Reproduction, UMR 1198 INRA/ENVA, 94704 Maisons-Alfort, \\ France; ${ }^{2}$ INRA, Biologie du Développement et Biotechnologies, UMR 1198 INRA/ENVA, 78352 Jouy en \\ Josas, France; and ${ }^{3}$ UCEA-INRA, Domaine de Bressonvilliers, 91630 Leudeville, France
}

\begin{abstract}
There have been few studies on a possible maternal influence on in vitro embryo production in cows. The objective of this study was to evaluate the maternal influence on oocyte production and in vitro blastocyst formation rate using repeated ovum pick-up and in vitro fertilization. Six contemporary cows raised on the same farm and with varied genetic origins were submitted to 42 weeks of ovum pickup organized into four series. Collected oocytes were fertilized in vitro with spermatozoa from a different bull for each series. In total, 1933 oocytes were recovered from 3936 follicles with a recovery rate of $57.2 \%$ and a mean oocyte collection of $4.6 \pm 0.2$ (mean \pm SEM) per animal per session. Animals were ranked according to their oocyte pro-
\end{abstract}

duction. The best oocyte donor was the same female in all four series. No relationship was identified between oocyte production and blastocyst production rate $(r=-0.08)$. The mean blastocyst rate was $28.8 \%$ with significant variation among animals. The best and the worst blastocyst producers were always the same animals independent of the semen used. The results of the present study support the hypothesis that in cattle, the oocyte donor influences the production of blastocysts. Furthermore, they demonstrate that oocyte and embryo production are independent factors. Further studies are necessary to identify the maternal or oocyte factors responsible for such differences.

\section{Introduction}

The formation of normal embryos with the capacity to develop to term requires both oocyte and spermatozoa. Both parental components influence the characteristics of the newly formed embryo; however, the cytoplasm of the early embryo is composed almost entirely of the cytoplasm from the oocyte. As an important female contribution to embryonic development, the ooplasm contains elements necessary for early embryonic development and an intrinsic cytoplasmic programme that regulates early embryo development (Waksmundzka et al., 1984). This gamete anisogamy has imposed asymmetry on the inheritance of cytoplasmic factors resulting in a widespread predominance of maternal inheritance of organelles, proteins, RNA transcripts and other factors. This potential of the oocyte is best exemplified by the ability of the bovine ooplasm to reprogramme the nuclei of somatic cells creating a state of totipotency supporting embryonic development, as in cloning (Renard, 1998; Kikyo and Wolffe, 2000).

During their growth phase, oocytes undergo a marked increase in size due to the accumulation of cytoplasmic proteins, mRNA, organelles and other macromolecules

Email: mtamassia@vet-alfort.fr that will be required for the initiation of development (Eppig, 2001). These maternally stored factors provide the necessary information for cell division during fertilization and the early stages of development. At this early stage, the induction of transcription inhibition does not prevent embryonic cleavage, indicating the total dependence of early development on maternal factors (for review, see Duranthon and Renard, 2003). These factors, which are stored in the oocytes, will sustain development from fertilization until the maternal-zygotic transition, which in cows occurs at the 16-cell stage (Telford et al., 1990; De Sousa et al., 1998). The importance of ooplasm inheritance is emphasized in the work of Renard et al. (1994) and Chastant et al. (1996) in which the source of oocyte cytoplasm affected blastocyst formation and gene expression.

In mice, both paternal (Shire and Whitten, 1980a) and maternal (Niwa et al., 1980; Shire and Whitten, 1980b; Renard et al., 1994) genetic factors have long been known to play a significant role in the time and rate of sperm penetration, fertilization, first cleavage, and blastocyst formation. Even though the large number of oocytes available from ovaries obtained from an abattoir facilitated the identification of paternal factors influencing bovine embryo production in vitro (Eid et al., 1994; Ward et al., 2001), the maternal influence has 
not been well documented. The paternal effect is seen at the first DNA replication cycle in which bulls with high blastocyst formation rate have longer replication cycles. These effects were not observed at fertilization or at the cleavage stage (Comizzoli et al., 2000). Conversely, studies that evaluate maternal influence on embryo production have been hampered for several reasons, among them the difficulty in obtaining large numbers of oocytes from the same female and the absence of inbred strains. The development of ultrasound guided follicular aspiration or ovum pick-up has proven to be a successful technique to collect oocytes repeatedly from live cows without affecting their future reproductive performance (Goto et al., 1988; Pieterse et al., 1988). This technique permits the production of oocytes that are genetically similar and allows comparative studies at the individual level to be performed.

In a large multiple ovulation embryo transfer retrospective study (1695 females and 2683 embryo collections), the maternal genetic ability to respond to superovulation was demonstrated (Govignon et al., 2000), as well as the contribution of recipient cattle to fertility after embryo transfer (McMillan and Donnison, 1999). Nevertheless, the maternal influence in oocyte production and on in vitro blastocyst production in cows remains undetermined. It was hypothesized that cows with varied genetic background have different capacities to produce oocytes by ovum pick-up and that their oocytes have different levels of competence for in vitro embryo production. The objective of this study was to estimate the variability between cows as oocyte donors and to identify different phenotypes for in vitro blastocyst formation.

\section{Materials and Methods}

\section{Animals}

Herd records were used to select six unrelated (that is without any common ancestor for at least two generations), contemporary, herd-mate Holstein cows as oocyte donors. They were all primiparous animals with similar milk. The animals received the same nutritional and health management from birth and throughout the experiment. These animals will be referred to in the text as animals $\mathrm{C} 1-\mathrm{C} 6$.

The ethical committee for experimentation with animals from the ENVA and from the INRA reviewed and approved the experimental protocol.

\section{Experimental design}

Ovum pick-up was performed over four series by the laboratory ovum pick-up team using standardized procedures. Oocytes collected during series 1, 2 and 3 were used for in vitro embryo production, whereas those from series 4 were used to evaluate fertilization rate.
Semen from three different bulls (two Holstein and one Normand) was used for in vitro embryo production, one for each series. For the evaluation of fertilization rate (series 4) the spermatozoa used was the same as that of the first IVF series. Bulls were selected after testing the semen in IVF trials using oocytes recovered from ovaries obtained from an abattoir; only semen showing consistently high blastocyst rates was selected. Throughout the study, IVF was performed by three trained technicians using standardized procedures. After IVF, embryos were co-cultured in vitro and blastocyst formation was observed on day 8 after IVF.

\section{Oocyte collection}

Before the first ovum pick-up session, the oestrous cycles of the animals were synchronized using progestagen implants and prostaglandin $\mathrm{F}_{2 \alpha}$, as prescribed by the manufacturer (CRESTAR ${ }^{\circledR}$ method; Intervet, Angers). Oocyte collection was performed twice a week (Gibbons et al., 1994; Bungartz et al., 1995; Garcia and Salaheddine, 1998; Galli et al., 2001) on Monday and Thursday, starting 5 days after implant removal without any other additional hormonal treatment to stimulate follicular growth. Series 1-4 lasted 14, 13, 6 and 9 consecutive weeks, respectively. Follicular aspiration was performed as described by Pieterse et al. (1988). Cows were restrained in extension locks and a low epidural anaesthesia $(5 \mathrm{ml}$ of $2 \%$ lidocaine; Xylovet, CEVA Sante Animale, Libourne) was administered $10 \mathrm{~min}$ before ovum pick-up. Ovarian follicles were visualized using an ultrasound scanner equipped with a $7.5 \mathrm{MHz}$ sectorial array transducer (Starvet 3, Pie Medical, Pouilly) placed in the cranial vagina and an 18-gauge short bevelled needle was used for follicular aspiration (Bols et al., 1996). Follicular contents were collected into a sterile $50 \mathrm{ml}$ tube (one tube per animal) containing $10 \mathrm{ml}$ of heparinized PBS (40 iu ml-1) and maintained at $37^{\circ} \mathrm{C}$ during the entire procedure. Once ovum pick-up was finished, the contents of the tubes were immediately filtered over a $100 \mu \mathrm{m}$ mesh and rinsed with warm $\left(37^{\circ} \mathrm{C}\right)$ PBS. Cumulus-oocyte complexes (COCs) were identified using a binocular stereoscope and transferred immediately into warm M199 supplemented with $10 \%$ fetal calf serum (FCS) (Life Technologies, Cergy).

\section{Classification of COCs}

COCs were classified according to their morphology into four categorical grades as described by de Loos et al. (1989) with some modifications as follows: (i) grade 1 (COC-1) corresponds to intact immature COCs with three or more layers of dense cumulus cells and homogeneous cytoplasm; (ii) grade 2 (COC-2) has fewer layers of compact cumulus investment or is a partially denuded oocyte with homogeneous cytoplasm; (iii) grade 3 
(COC-3) is a denuded immature oocyte that has lost its cumulus cells but sustains a homogeneous cytoplasm or oocyte with some minor irregularities in the cytoplasm; and (iv) grade 4 (COC-4) consists of mature or degenerated oocytes as well as oocytes with irregular ooplasm presenting dark areas. Oocytes with fragmented cytoplasm and cracked zona pellucida as well as COCs with abnormal or expanded cumulus investments were also graded 4 and these oocytes were eliminated from the experiment.

\section{In vitro maturation, fertilization and development}

In vitro maturation and fertilization conditions were kept constant in the four experiments as described by Menck et al. (1997). The COCs graded 1, 2 and 3 from each animal were matured in vitro for $22-24 \mathrm{~h}$ into $50 \mu \mathrm{l}$ microdrops (one microdrop for each oocyte donor) of M199 supplemented with 10\% FCS, $10 \mu \mathrm{g} \mathrm{FSH}$ $\mathrm{ml}^{-1}, 10 \mu \mathrm{g} \mathrm{LH} \mathrm{ml}{ }^{-1}$ and $1 \mu \mathrm{g}$ oestradiol $\mathrm{ml}^{-1}$ (Sigma, St Quentin-Fallavier), over a layer of Vero cells (RhoneMérieux, Lyon) to improve maturation of denuded oocytes (Grocholova et al., 1995). Oocytes from all six animals were processed at the same time, kept under a controlled atmosphere $\left(5 \% \mathrm{CO}_{2}\right.$ in air) and cultured in the same incubator.

After maturation, oocytes were fertilized in vitro (day 0) using frozen semen (same ejaculate) from a single bull. The spermatozoa from one thawed straw were selected by swim-up (Parrish et al., 1986) and each microdrop was inseminated to a final concentration of $1.0 \times 10^{6}$ spermatozoa $\mathrm{ml}^{-1}$. Presumptive zygotes were mechanically freed from their cumulus cells by gentle pipetting at $22 \mathrm{~h}$ after insemination. After rinsing, all oocytes exposed to spermatozoa were co-cultured in $50 \mu \mathrm{l}$ microdrops of B2 medium (CCD, Paris) supplemented with $2.5 \%$ FCS containing a monolayer of Vero cells according to the routine used in the laboratory (Menck et al., 1997). Cleavage rate was observed at day 2 and blastocyst formation at days 6, 7 and 8 .

Fertilization rate was specifically investigated with 18 additional ovum pick-up sessions in four animals which were selected based on their blastocyst production (series 4). The same maturation and fertilization techniques described above were used and oocytes were allowed to remain in the presence of spermatozoa for 13,15 and $17 \mathrm{~h}$ before fixation. After fertilization, all presumptive zygotes were rinsed in M199 with 10\% FCS and then fixed in $2.5 \%$ paraformaldehyde (Sigma) at room temperature for $15 \mathrm{~min}$ before they were rinsed in PBS and stored at $4^{\circ} \mathrm{C}$ overnight. DNA from the zygotes was stained with Hoechst $33342\left(10 \mu \mathrm{g} \mathrm{ml}^{-1}\right.$, Sigma $)$ in PBS at $39^{\circ} \mathrm{C}$ for $5 \mathrm{~min}$. Zygotes were then mounted on glass slides with an anti-fading agent (Vectashield, Vector Laboratories, Abcys) for observation with an inverted microscope fitted for fluorescence and the presence and number of pronuclei were recorded.

\section{Statistical analysis}

Cows were compared for the number and percentage of oocytes recovered (series 1-4), fertilization rates (series 4), cleavage rate (number of cleaved embryos divided by the number of fertilized oocytes in co-culture) and blastocyst rate (in series 1-3 and defined as the number of blastocysts present at day 8 divided by the number of fertilized oocytes in co-culture). Cows were ranked using the Gabriel post hoc test by a comparison of means using ANOVA (SPSS release 10.0.1; SPSS Inc., Chicago). The model used included cow as the independent variable and the remaining variables as dependent variables. Pearson correlations among animals within- and between-experimental sessions for oocyte quality, cleavage rate and blastocyst rate were calculated as well as the oocyte recovery rate. Although ovum pick-up and IVF operators used standardized procedures throughout the experiment, they were also included in the model. All results are presented as mean \pm SEM unless otherwise stated; values with different superscripts are statistically different $(P<0.05)$.

\section{Results}

\section{Oocyte production (series 1-4)}

Overall results. During the 42 weeks in which ovum pick-up was performed, 1933 oocytes were recovered from 3936 follicles with a mean recovery rate of $57.2 \%$ revealing a strong positive relationship $(r=0.4$; $P<0.01$ ). A mean number of $9.3 \pm 0.2$ follicles was aspirated with $4.6 \pm 0.2$ oocytes recovered per session per animal. From the recovered oocytes $82.1 \%$ were graded as COC- 1 and $-2,10.1 \%$ as COC-3 and $7.8 \%$ as COC-4 (Fig. 1).

No differences among ovum pick-up operators were observed, although ovum pick-up was considerably more difficult in some cows.

Individual results. Individual mean oocyte production varied significantly in quantity but not in quality (proportion of each COC grade) among animals (Fig. 1). After ranking animals for oocyte production, it was observed that animal $\mathrm{C} 5$ had the lowest mean oocyte production whereas $\mathrm{C} 2$ had the best mean oocyte production per ovum pick-up session (Fig. 2). Cows were statistically ranked for oocyte production in each series and results showed that the statistical rank order remained virtually unchanged among the four series (Table 1). The number of oocytes recovered in each ovum pick-up session varied widely among animals, and the curves for most cows were non-symmetrical (skewness $\pm \mathrm{SEM}=0.3 \pm 0.3$, $1.2^{*} \pm 0.3,0.8^{*} \pm 0.3,0.7^{*} \pm 0.3,1.1^{*} \pm 0.3,0.6 \pm 0.3$ for cows $\mathrm{C} 1-\mathrm{C} 6$, respectively; ${ }^{*}$ indicates deviation from normality). This is illustrated by the shape of the distribution curve and the standard deviation values (Figs 2 and 3). For each animal there was a significant positive 


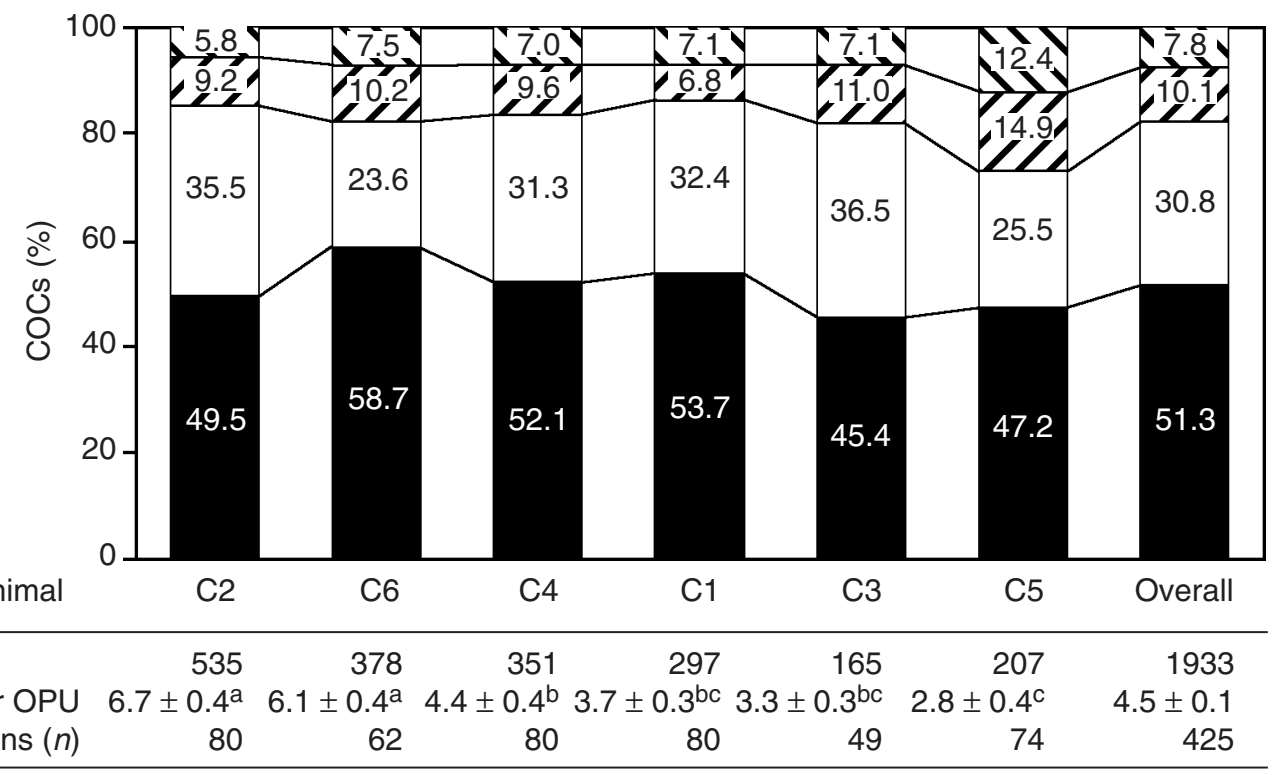

Fig. 1. Cumulative recovery rate of cumulus-oocyte complexes (COCs) for each cow (C1-C6) in experimental

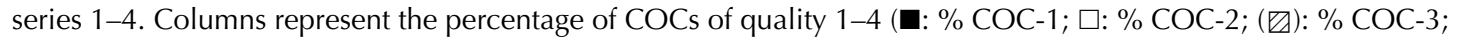

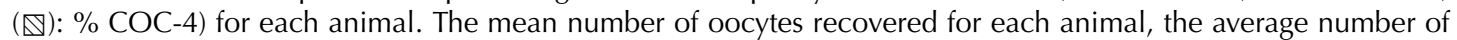
oocytes per ovum pick-up (OPU) session $( \pm$ SEM) and the overall average of all animals are shown. Animals are ranked according to the number of oocytes recovered per OPU session.

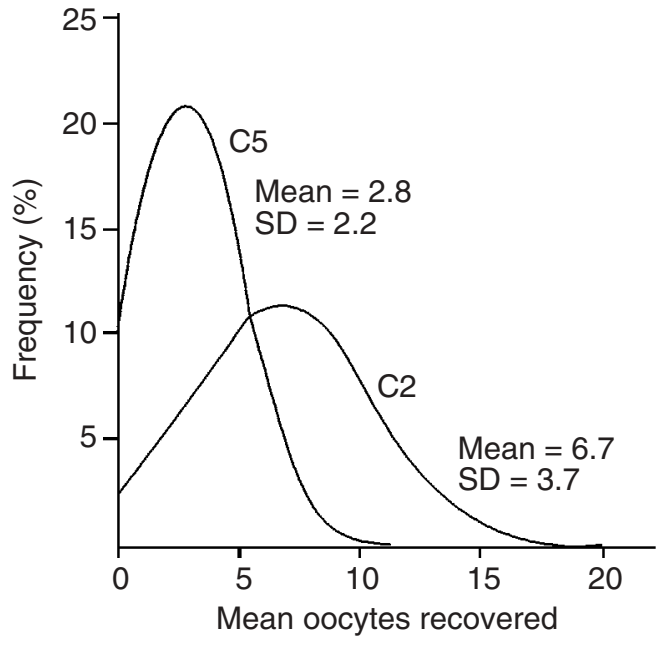

Fig. 2. Distribution curve of oocytes recovered from the best (cow C2) and the worst (cow C5) oocyte producers. For each animal, the mean numbers of oocytes recovered and the standard deviation are indicated.

correlation between the number of follicles aspirated and the number of oocytes recovered, except in animal C4 $(r=0.19)$.

\section{Embryo production (series 1-3)}

Overall results. Mean overall cleavage rate was $79.2 \%$ whereas the mean overall blastocyst rate was $28.8 \%$
(Table 2). A total of 532, 613 and 190 oocytes were fertilized in vitro in series 1,2 and 3, respectively. The mean cleavage rate was $87.2 \%, 71.5 \%$ and $77.2 \%$, with mean blastocyst rates of $35.8 \%, 19.8 \%$ and $31.1 \%$ for series 1,2 and 3, respectively. Factors such as ovum pick-up operator and IVF technician did not significantly affect the results.

Fertilization rate. Overall, fertilization rate was $75.0 \%$ with the following individual rates: $66.7 \%(n=24)$, $76.6 \%(n=47), 73.9 \%(n=46), 92.9 \%(n=14)$ and $74.8 \%(n=143)$ for animals C1, C2, C4, C5 and control, respectively. Fertilization rate did not differ among the four animals studied, independently of time of observation (13, 15 or $17 \mathrm{~h}$ after insemination). The overall rate of polyspermy was $5.1 \%$ and no animal differed significantly from this mean value.

Cleavage rate. Cleavage rates were not significantly different among the animals in all series (Table 3). Altogether, the number of recovered oocytes and cleavage rate showed a negative relationship $(r=-0.13 ; P<0.05)$; this was mainly due to animal $\mathrm{C} 4$, which was the only animal showing a significant correlation $(r=-0.29$; $P<0.05)$, whereas the other animals showed negative but non-significant correlations.

In vitro development: individual results. Cleavage and blastocyst rates for each female are presented (Table 2). No significant difference was observed for cleavage rate 
Table 1. Cows (C1-C6) ranked according to mean oocyte production in each experimental series

\begin{tabular}{|c|c|c|c|c|c|c|}
\hline Series 1 & $\begin{array}{c}\text { C5 } \\
3.1 \pm 0.4^{\mathrm{a}}\end{array}$ & $\begin{array}{c}C 1 \\
3.6 \pm 0.4^{\mathrm{ab}}\end{array}$ & $\begin{array}{c}C 3 \\
4.0 \pm 0.6^{\mathrm{ab}}\end{array}$ & $\begin{array}{c}C 4 \\
4.2 \pm 0.5^{\mathrm{ab}}\end{array}$ & $\begin{array}{c}\text { C6 } \\
5.7 \pm 0.6^{\mathrm{bc}}\end{array}$ & $\begin{array}{c}C 2 \\
6.7 \pm 0.6^{c}\end{array}$ \\
\hline Series 2 & $\begin{array}{c}\mathrm{C} 3 \\
3.5 \pm 0.6^{\mathrm{a}}\end{array}$ & $\begin{array}{c}\mathrm{C} 5 \\
4.2 \pm 0.6^{\mathrm{a}}\end{array}$ & $\begin{array}{c}C 4 \\
5.4 \pm 0.5^{\mathrm{ab}}\end{array}$ & $\begin{array}{c}C 1 \\
5.5 \pm 0.5^{\mathrm{ab}}\end{array}$ & $\begin{array}{c}\mathrm{C} 6 \\
7.6 \pm 0.8^{\mathrm{bc}}\end{array}$ & $\begin{array}{c}C 2 \\
8.6 \pm 1.0^{\circ}\end{array}$ \\
\hline Series 3 & $\begin{array}{c}\text { C5 } \\
2.2 \pm 0.5^{\mathrm{a}}\end{array}$ & $\begin{array}{c}\text { C3 } \\
2.3 \pm 0.4^{\mathrm{a}}\end{array}$ & $\begin{array}{c}C 1 \\
2.7 \pm 0.5^{a}\end{array}$ & $\begin{array}{c}\text { C6 } \\
4.0 \pm 0.6^{\mathrm{ab}}\end{array}$ & $\begin{array}{c}C 4 \\
4.3 \pm 0.7^{\mathrm{ab}}\end{array}$ & $\begin{array}{c}C 2 \\
5.6 \pm 0.6^{b}\end{array}$ \\
\hline Series 4 & $\begin{array}{c}\text { C5 } \\
1.4 \pm 0.3^{\mathrm{a}}\end{array}$ & $\begin{array}{c}\mathrm{C} 1 \\
2.2 \pm 0.4^{\mathrm{ab}}\end{array}$ & $\begin{array}{c}\mathrm{C} 4 \\
3.4 \pm 0.4^{\mathrm{b}}\end{array}$ & $\begin{array}{c}C 2 \\
4.9 \pm 0.7^{c}\end{array}$ & & \\
\hline
\end{tabular}

Values indicate the mean number of oocytes collected per ovum pick-up session for that animal $( \pm S E M)$.

Values in the same row with a different superscript are significantly different $(P<0.05)$.

Table 2. Cows (C1-C6) ranked according to the overall blastocyst rate in experimental series 1-3 in which IVF was performed

\begin{tabular}{|c|c|c|c|c|c|c|}
\hline Cow & $\begin{array}{l}\text { Number of } \\
\text { IVF sessions }\end{array}$ & $\begin{array}{l}\text { Oocytes } \\
\text { in IVF }\end{array}$ & $\begin{array}{c}\text { Mean cleavage } \\
\text { rate }(\%)\end{array}$ & $\begin{array}{c}\text { Mean blastocyst } \\
\text { rate }(\%)\end{array}$ & $\begin{array}{l}\text { Total number } \\
\text { of blastocysts }\end{array}$ & $\begin{array}{l}\text { Blastocysts per } \\
\text { IVF session }\end{array}$ \\
\hline C5 & 42 & 123 & $88.1 \pm 3.5$ & $52.4 \pm 6.2^{\mathrm{a}}$ & 62 & $1.5 \pm 0.2^{\mathrm{ab}}$ \\
\hline $\mathrm{C} 1$ & 53 & 207 & $83.6 \pm 3.4$ & $35.2 \pm 4.6^{\mathrm{ab}}$ & 71 & $1.3 \pm 0.2^{\mathrm{abc}}$ \\
\hline $\mathrm{C} 2$ & 55 & 350 & $77.8 \pm 3.9$ & $32.4 \pm 3.6^{b}$ & 111 & $2.0 \pm 0.3^{\mathrm{a}}$ \\
\hline $\mathrm{C} 3$ & 38 & 121 & $72.5 \pm 5.3$ & $25.5 \pm 4.9^{b c}$ & 32 & $0.8 \pm 0.2^{\mathrm{bc}}$ \\
\hline C6 & 56 & 301 & $80.6 \pm 3.1$ & $20.3 \pm 3.1^{b c}$ & 58 & $1.0 \pm 0.1^{\mathrm{bc}}$ \\
\hline C4 & 55 & 233 & $73.0 \pm 4.1$ & $11.7 \pm 2.6^{c}$ & 29 & $0.5 \pm 0.1^{\mathrm{c}}$ \\
\hline Total & 56 & 1335 & $79.2 \pm 1.6$ & $28.8 \pm 1.8$ & 363 & $1.2 \pm 0.1$ \\
\hline
\end{tabular}

Values in the same column with a different superscript are significantly different $(P<0.05)$.

Animals are ranked on the basis of blastocyst production.
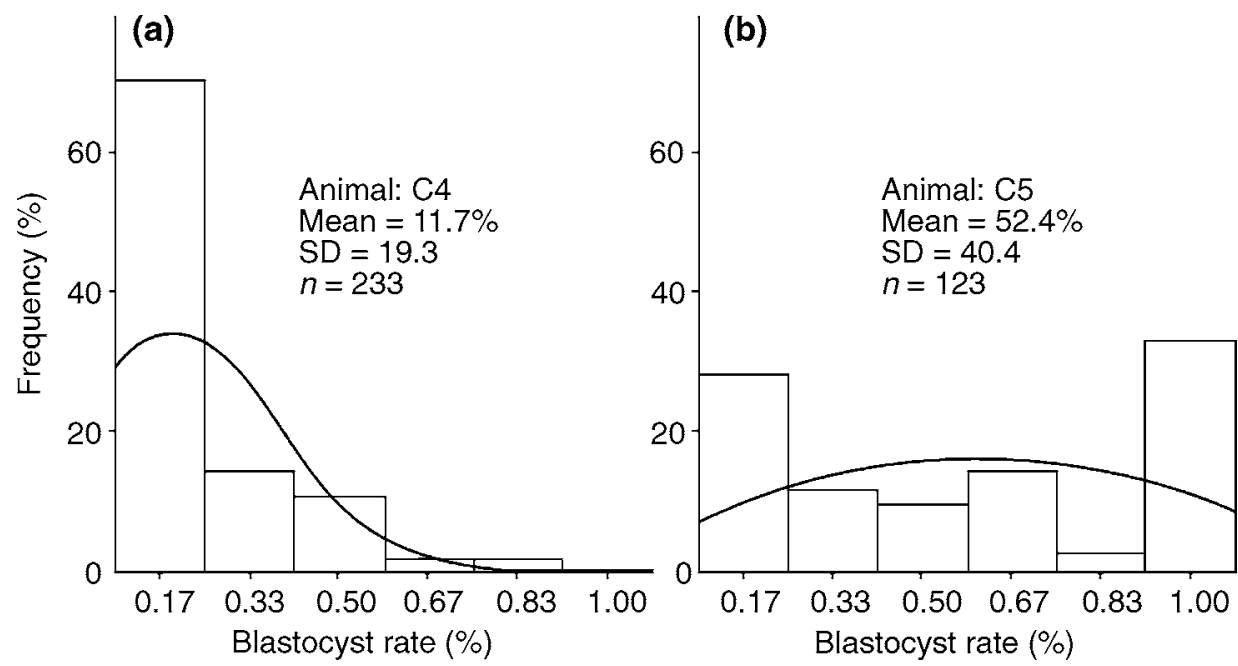

Fig. 3. Distribution of blastocyst formation rate from animals with extreme phenotypes for blastocyst production. Cow $\mathrm{C} 4$ and cow $\mathrm{C} 5$ were the worst and the best blastocyst producer, respectively. Bars represent the frequency of IVF sessions for blastocyst production (in intervals of $17 \%$ ). The mean blastocyst production, the standard deviation and the total number of blastocysts produced in all three experimental sessions are shown.

among cows. When each series was analysed separately, the only significant difference found in cleavage rate was for series 3 , in which animal C4 had a lower cleavage rate than animal C5 (57.5\% versus $95.8 \% ; P<0.05$, respectively). On the other hand, significant differences were observed for blastocyst rate between females, as indicated in Fig. 3, in which the blastocyst production profiles for the best and worst cows are represented. 
Table 3. Cows (C1-C6) ranked according to the blastocyst rate (\%) in each experimental series

\begin{tabular}{|c|c|c|c|c|c|c|}
\hline $\begin{array}{l}\text { Series } 1 \\
\text { Semen A }\end{array}$ & $\begin{array}{c}\text { C4 } \\
15.1 \pm 4.7^{\mathrm{ab}}\end{array}$ & $\begin{array}{c}\text { C6 } \\
21.4 \pm 4.1^{\mathrm{ab}}\end{array}$ & $\begin{array}{c}\text { C3 } \\
29.6 \pm 8.0^{\mathrm{ab}}\end{array}$ & $\begin{array}{c}C 2 \\
44.5 \pm 5.7^{b c}\end{array}$ & $\begin{array}{c}\mathrm{C} 1 \\
47.5 \pm 7.5^{\mathrm{bc}}\end{array}$ & $\begin{array}{c}\text { C5 } \\
58.3 \pm 9.5^{\mathrm{c}}\end{array}$ \\
\hline $\begin{array}{l}\text { Series } 2 \\
\text { Semen B }\end{array}$ & $\begin{array}{c}C 4 \\
8.7 \pm 3.3^{\mathrm{a}}\end{array}$ & $\begin{array}{c}C 3 \\
12.6 \pm 6.4^{\mathrm{a}}\end{array}$ & $\begin{array}{c}\text { C6 } \\
19.0 \pm 6.0^{\mathrm{ab}}\end{array}$ & $\begin{array}{c}C 2 \\
20.2 \pm 4.8^{\mathrm{ab}}\end{array}$ & $\begin{array}{c}\text { C1 } \\
24.3 \pm 6.0^{\mathrm{ab}}\end{array}$ & $\begin{array}{c}\text { C5 } \\
39.5 \pm 10.1^{b}\end{array}$ \\
\hline $\begin{array}{l}\text { Series } 3 \\
\text { Semen C }\end{array}$ & $\begin{array}{c}C 4 \\
10.0 \pm 5.6^{\mathrm{a}}\end{array}$ & $\begin{array}{c}\text { C6 } \\
20.6 \pm 6.4^{\mathrm{a}}\end{array}$ & $\begin{array}{c}C 2 \\
28.3 \pm 6.6^{\mathrm{ab}}\end{array}$ & $\begin{array}{c}\mathrm{C} 1 \\
31.3 \pm 11.2^{\mathrm{ab}}\end{array}$ & $\begin{array}{c}\text { C3 } \\
44.4 \pm 10.4^{\mathrm{ab}}\end{array}$ & $\begin{array}{c}\text { C5 } \\
60.4 \pm 13.3^{b}\end{array}$ \\
\hline
\end{tabular}

Semen from a different bull was used in each experimental series (semen A, B and C).

Values are the mean blastocyst rate obtained for that animal in that series ( \pm SEM).

Values in the same row with a different superscript are significantly different $(P<0.05)$.

When cows were statistically ranked according to blastocyst production, it was observed that the order remained practically the same in the three series (Table 3), whereby the best cow was always the best and the worst cow always the worst producer of blastocysts in each series.

For all animals, no correlation was observed between the number of oocytes recovered and blastocyst production $(r=-0.08)$. On the contrary, cleavage rate and blastocyst rate showed a strong positive relationship $(r=0.39 ; P<0.01)$. Only animals $\mathrm{C} 3$ and $\mathrm{C} 4$ failed to show a significant relationship $(r=0.29$ and $r=0.17$, respectively). There was roughly a fourfold difference in the number of blastocysts per animal per IVF session between females (Table 2) ranging from 0.5 and 2.0 blastocysts per IVF session. Blastocyst formation rates of animals C1, C2 and C5 followed a normal distribution (skewness $\pm \mathrm{SEM}=0.6 \pm 0.3, \quad 0.6 \pm 0.3, \quad-0.1 \pm 0.4$ ), whereas animals $\mathrm{C} 3, \mathrm{C} 4$ and $\mathrm{C} 6$ deviated from normality (skewness \pm SEM $=0.9 \pm 0.4,1.5 \pm 0.3,1.2 \pm 0.3$ ).

\section{Discussion}

The present study was designed to evaluate the influence of the oocyte donor cow on the number of oocytes recovered and blastocyst formation rate using repeated ovum pick-up and IVF on the same cows, from different genetic origins. The data showed a distinctive variation in number of oocytes recovered by ovum pick-up per cow allowing the classification of some cows as systematically 'good' or 'bad' oocyte producers. The same effect was also observed for blastocyst production, with cows showing a phenotype of 'good' or 'bad' blastocyst producer. The semen used did not influence extreme phenotypes for blastocyst rate, revealing a maternal influence on bovine embryo development.

The oocyte recovery rate in the present study is consistent with the results reported by Garcia and Salaheddine (1998) but lower than those observed by Bungartz et al. (1995) and Bols et al. (1996). The number of aspirated follicles and oocytes recovered reported here were influenced by the presence of animals with different phenotypes for oocyte production, a phenomenon also observed by Kruip et al. (1994) and a factor observed in certain family lines (Bruggerhoff et al., 2002). Hasler et al. (1995) reported an animal-induced variation in the number of oocytes recovered as well as in the blastocyst rate, which was of a similar magnitude to the variations described above. Boni et al. (1997) identified a repeatable and predictable large variation in follicular recruitment between animals after several months of repeated ovum pick-up. The strong correlation found between the number of follicles aspirated and oocytes recovered in the present study leads the authors to believe that the variation in the quantity of oocytes recovered among animals is directly related to the variation in follicular recruitment. With the procedures described above, it was possible to successfully identify animals with different phenotypes (high, average or low) for oocyte production.

It is known that ovum pick-up conditions can influence the quality of the oocytes recovered (Kruip et al., 1994; Bols et al., 1996; Fry et al., 1997; Hashimoto et al., 1999). A significant variation in the quality of COCs recovered among animals was not observed in the present study; however, the vast majority of the COCs recovered were of good quality (grades 1 and 2). This absence of variation was due to the strict ovum pick-up conditions followed in each experiment and the small group of ovum pick-up technicians. The quality of the oocytes recovered by ovum pick-up also reflects the process of follicular recruitment and selection that eliminates faulty oocytes (Picton, 2001; Beg et al., 2002; Markstrom et al., 2002), although this effect is difficult to quantify because even a healthy follicle may contain an incompetent oocyte (Blondin and Sirard, 1995). As ovum pick-up was performed twice a week, the oocytes recovered were not subjected to the suppressive effects of a dominant follicle and oestrus and, therefore, were of good quality. Thus, the recovery of cumulus expanded oocytes or oocytes from atretic follicles was markedly reduced.

The animals that had high numbers of grade 1 and 2 oocytes did not have the expected higher blastocyst rates. This finding contradicts to some extent the observations made by Hashimoto et al. (1998) that developmental competence of bovine oocytes is induced in a cell 
density-dependent manner. This apparent difference can be explained by the origin of the oocytes. Whereas the present study used oocytes from the same animal, that is oocytes with the same cytoplasm and genetic background, Hashimoto et al. (1998) used oocytes recovered from ovaries obtained from an abattoir. This precluded the observation of individual animal effects, making COC morphology the only reliable variable to be considered. Furthermore, Boni et al. (2002) recently demonstrated that in cows, not only is morphological classification of COCs related to developmental competence, but also to other factors such as plasma membrane $\mathrm{Ca}^{2+}$ current (in the immature oocytes) and calcium stores (in mature oocytes). Tanghe et al. (2003) demonstrated that the maturation and fertilization rate of denuded oocytes are significantly improved if they are co-cultured in the presence of a monolayer of cumulus cells or placed in culture medium conditioned by the same cells. The role that the co-culture with Vero cells had in improving the maturation conditions of oocytes (mainly for single or denuded oocytes) is difficult to assess and is a potential variation factor.

The oocyte-origin effect over blastocyst production was not related to its ability to be fertilized, as observed by the high fertilization and cleavage rates obtained for all females. Nonetheless, a trend was observed: animals with high blastocyst production also had higher fertilization and cleavage rates than animals with a low blastocyst rate (data not shown). The maternal factors present in the ooplasm have direct effects on embryo fertilization and its kinetics (Renard et al., 1994; Duranthon and Renard, 2003) and they provide the oocyte with the molecules necessary in the control of embryonic development until the embryonic genome takes over (Telford et al., 1990; McCarthy and Ward, 2000; Miller, 2000; Oh et al., 2000). However, the spermatozoon should not be considered merely as a vector for paternal DNA as it carries a number of cytoplasmic factors that are essential for normal early fertilization (Wu et al., 1998; Knott et al., 2002). The observed variations in overall and individual mean blastocyst rates in all three series in which semen from different bulls was used clearly shows the paternal influence. This observed semen-induced variation is in agreement with that reported in the literature (Comizzoli et al., 2000; Ward et al., 2001). Comizzoli et al. (2000) did not observe a maternal genotype influence over time for onset of the first DNA replication in their work. Although the present study did not investigate the timing of onset of replication, the results show that the maternal influence is expressed during the later stages of development (no difference in fertilization and cleavage rate). Moreover, they used few randomly chosen females in their study; this might have masked the identification of females with different phenotypes, as could have been the case if fewer non-selected animals had been used in the present study. These sperm-induced variations only emphasize the maternal contribution as the best and worst blastocyst producers were always the same females.

The present data clearly show that the donor cow influences the quality of the oocyte, as measured by its ability to develop to the blastocyst stage in vitro. This is highlighted by the observation that the position of animals $\mathrm{C} 4$ and $\mathrm{C} 5$, when ranked for blastocyst rate in each experiment, was unchanged. In addition, animal C4 had a strong positively skewed distribution for blastocyst rate, indicative of a high incidence of IVF without blastocyst production. These differences may enable the development of a more rapid method for identifying animals with this phenotype. Animals with different blastocyst formation rates were also reported by Kruip et al. (1994) but they did not identify a maternal effect. At the present time, the heritability of the isolated phenotypes remains unknown and demands additional investigation, as there is evidence that it may be a transmissible characteristic (Bruggerhoff et al., 2002).

The number of blastocysts produced per ovum pickup session was in the range achieved by others (Kruip et al., 1994; Hasler et al., 1995). However, in the present study it was observed that high oocyte production does not necessarily imply a higher blastocyst production rate but may result in a higher number of blastocysts. The lack of correlation between number of oocytes recovered and blastocyst rate shows the independence of the two factors measured. Moreover, the results showed that the animal with the best blastocyst rate was the worst oocyte producer; furthermore, this cow ranked third in total number of blastocysts produced. Meanwhile, the best oocyte producer had an average blastocyst rate making it the most productive cow. In short, when selecting animals for in vitro embryo production using the techniques described above, maximum yield will be achieved only if a compromise between selection for oocyte production and blastocyst rate is established.

At this point, it is not possible to identify the origin of this maternal effect as it could be of genetic, nuclear (Watson et al., 1999; Picton, 2001) or cytoplasmic origin (Cummins, 2001; Duranthon and Renard, 2003). The results of the present study support the hypothesis of a maternal influence on oocyte and blastocyst production in vitro. The selection of animals with different in vitro production phenotypes will permit comparative studies on the quantification of mitochondria in each oocyte and on the evaluation of mRNA and ATP, in an attempt to identify the origin of such differences in developmental competence.

The authors thank C. Shipley for his critical reading of the manuscript and comments. In addition, the authors gratefully acknowledge the help provided by the ovum pick-up technical team at the INRA experimental station of Bressonvilliers. This work was funded by the Biology of Reproduction laboratory at the Ecole Nationale Vétérinaire D'Alfort. A portion of the study was presented at the 17 th reunion of the Association Européenne de Transfert Embryonnaire. 


\section{References}

Beg MA, Bergfelt DR, Kot K and Ginther OJ (2002) Follicle selection in cattle: dynamics of follicular fluid factors during development of follicle dominance Biology of Reproduction 66 120-126

Blondin P and Sirard MA (1995) Oocyte and follicular morphology as determining characteristics for developmental competence in bovine oocytes Molecular Reproduction and Development 41 54-62

Bols PE, Van Soom A, Ysebaert MT, Vandenheede JMM and de Kruif A (1996) Effects of aspiration vacuum and needle diameter on cumulusoocyte complex morphology and developmental capacity of bovine oocytes Theriogenology 45 1001-1014

Boni R, Roelofsen MWM, Pieterse MC, Kogut J and Kruip TA (1997) Follicular dynamics, repeatability and predictability of follicular recruitment in cows undergoing repeated follicular puncture Theriogenology 48227 289

Boni R, Cuomo A and Tosti E (2002) Developmental potential in bovine oocytes is related to cumulus-oocyte complex grade, calcium current activity, and calcium stores Biology of Reproduction 66 836-842

Bruggerhoff K, Zakhartchenko V, Wenigerkind H et al. (2002) Bovine somatic cell nuclear transfer using recipient oocytes recovered by ovum pick-up: effect of maternal lineage of oocyte donors Biology of Reproduction 66 367-373

Bungartz L, Lucas-Hahn A, Rath D and Niemann H (1995) Collection of oocytes from cattle via follicular aspiration aided by ultrasound with or without gonadotropin pretreatment and in different reproductive stages Theriogenology 43 667-675

Chastant S, Christians E, Campion E and Renard JP (1996) Quantitative control of gene expression by nucleocytoplasmic interactions in early mouse embryos: consequence for reprogrammation by nuclear transfer Molecular Reproduction and Development 44 423-432

Comizzoli P, Marquant-Le Guienne B, Heyman Y and Renard JP (2000) Onset of the first S-phase is determined by a paternal effect during the G1-phase in bovine zygotes Biology of Reproduction 62 16771684

Cummins JM (2001) Cytoplasmic inheritance and its implications for animal biotechnology Theriogenology 55 1381-1399

De Loos F, van Vliet C, van Maurik P and Kruip TA (1989) Morphology of immature bovine oocytes Gamete Research 24 197-204

De Sousa PA, Caveney A, Westhusin ME and Watson AJ (1998) Temporal patterns of embryonic gene expression and their dependence on oogenetic factors Theriogenology 49 115-128

Duranthon V and Renard JP (2003) Storage and functional recovery of molecules in oocytes. In Biology and Pathology of the Oocyte pp 81105. Cambridge University Press, Cambridge

Eid LN, Lorton SP and Parrish JJ (1994) Paternal influence on S-phase in the first cell cycle of the bovine embryo Biology of Reproduction $\mathbf{5 1}$ $1232-1237$

Eppig JJ (2001) Oocyte control of ovarian follicular development and function in mammals Reproduction 122 829-938

Fry RC, Niall EM, Simpson TL, Squires TJ and Reynolds J (1997) The collection of oocytes from bovine ovaries Theriogenology 47 977-987

Galli C, Crotti G, Notari C, Turini P, Duchi R and Lazzari G (2001) Embryo production by ovum pick up from live donors Theriogenology $\mathbf{5 5} 1341$ 1357

Garcia A and Salaheddine M (1998) Effects of repeated ultrasoundguided transvaginal follicular aspiration on bovine oocyte recovery and subsequent follicular development Theriogenology 50 575-585

Gibbons JR, Beal WE, Krisher RL, Faber EG, Pearson RE and Gwazdauskas FC (1994) Effects of once versus twice weekly transvaginal follicular aspiration on bovine oocyte recovery and embryo development Theriogenology 42 405-419

Goto K, Kajihara Y, Kosaka S, Koba M, Nakanishi Y and Ogawa K (1988) Pregnancies after co-culture of cumulus cells with bovine embryos derived from in vitro fertilization of in vitro matured follicular oocytes Journal of Reproduction and Fertility 83 753-758

Govignon A, Rohou A, Ponsart C, Delcroix P and Humblot P (2000) Sources of variation of embryo production after superovulation in Prim Holstein dairy cows. In 16eme Réunion de la A.E.T.E. p. 158 Santander
Grocholova B, Petr J, Marek J and Tepla O (1995) Beneficial influence of Vero cells on in vitro maturation and fertilization of bovine oocytes Theriogenology 44 199-207

Hashimoto S, Saeki K, Nagao Y, Minami N, Yamada M and Utsumi K (1998) Effects of cumulus cell density during in vitro maturation of the developmental competence of bovine oocytes Theriogenology 491451 1463

Hashimoto S, Takakura R, Minami N and Yamada M (1999) Ultrasoundguided follicle aspiration: effect of the frequency of a linear transvaginal probe on the collection of bovine oocytes Theriogenology 52 131138

Hasler JF, Henderson WB, Hurtgen PJ, Jin ZQ, McCauley AD, Mower SA, Neely B, Shuey LS, Stokes JE and Trimmer SA (1995) Production, freezing and transfer of bovine embryos and subsequent calving results Theriogenology 43 141-152

Kikyo N and Wolffe AP (2000) Reprogramming nuclei: insights from cloning, nuclear transfer and heterokaryons Journal of Cell Science $113(\mathrm{Pt} 1) 11$ 20

Knott JG, Poothapillai K, Wu H, He CL, Fissore RA and Robl JM (2002) Porcine sperm factor supports activation and development of bovine nuclear transfer embryos Biology of Reproduction 66 1095-1103

Kruip TA, Boni R, Wurth YA, Roelofsen MWM and Pieterse MC (1994) Potential use of ovum pick-up for embryo production and breeding in cattle Theriogenology 42 675-684

McCarthy S and Ward WS (2000) Interaction of exogenous DNA with the nuclear matrix of live spermatozoa Molecular Reproduction and Development 56 235-237

McMillan WH and Donnison MJ (1999) Understanding maternal contributions to fertility in recipient cattle: development of herds with contrasting pregnancy rates Animal Reproduction Science 57 127-140

Markstrom E, Svensson E, Shao R, Svanberg B and Billig H (2002) Survival factors regulating ovarian apoptosis - dependence on follicle differentiation Reproduction 123 23-30

Menck MC, Guyader-Joly C, Peynot N, Le Bourhis D, Lobo RB, Renard JP and Heyman Y (1997) Beneficial effects of Vero cells for developing IVF bovine eggs in two different coculture systems Reproduction, Nutrition and Development 37 141-150

Miller D (2000) Analysis and significance of messenger RNA in human ejaculated spermatozoa Molecular Reproduction and Development $\mathbf{5 6}$ 259-264

Niwa K, Araki M and Iritani A (1980) Fertilization in vitro of eggs and first cleavage of embryos in different strains of mice Biology of Reproduction 22 1155-1159

Oh B, Hwang S, McLaughlin J, Solter D and Knowles BB (2000) Timely translation during the mouse oocyte-to-embryo transition Development 127 3795-3803

Parrish JJ, Susko-Parrish JL, Leibfried-Rutledge ML, Critse ES, Eyestone WH and First NL (1986) Bovine in vitro fertilization with frozen-thawed semen Theriogenology 25 591-600

Picton HM (2001) Activation of follicle development: the primordial follicle Theriogenology 55 1193-1210

Pieterse MC, Kappen KA, Kruip TA and Taverne MA (1988) Aspiration of bovine oocytes during transvaginal ultrasound scanning of the ovaries Theriogenology $30751-762$

Renard JP (1998) Chromatin remodelling and nuclear reprogramming at the onset of embryonic development in mammals Reproduction, Fertility and Development 10 573-580

Renard JP, Baldacci P, Richoux-Duranthon V, Pournin S and Babinet C (1994) A maternal factor affecting mouse blastocyst formation Development 120 797-802

Shire JG and Whitten WK (1980a) Genetic variation in the timing of first cleavage in mice: effect of paternal genotype Biology of Reproduction 23 363-368

Shire JG and Whitten WK (1980b) Genetic variation in the timing of first cleavage in mice: effect of maternal genotype Biology of Reproduction 23 369-376

Tanghe S, Van Soom A, Mehrzad J, Maes D, Duchateau L and de Kruif A (2003) Cumulus contributions during bovine fertilization in vitro. Theriogenology 60 135-149 
Telford NA, Watson A and Schultz GA (1990) Transition from maternal to embryonic control in early mammalian development: a comparison of several species Molecular Reproduction and Development 26 90100

Waksmundzka M, Krysiak E, Karasiewicz J, Czolowska $\mathbf{R}$ and Tarkowski AK (1984) Autonomous cortical activity in mouse eggs controlled by a cytoplasmic clock Journal of Embryology and Experimental Morphology $7977-96$

Ward F, Rizos D, Corridan D, Quinn K, Boland M and Lonergan P (2001) Paternal influence on the time of first embryonic cleavage post insemination and the implications for subsequent bovine embryo development in vitro and fertility in vivo. Molecular Reproduction and Development 60 47-55
Watson AJ, Westhusin ME, De Sousa PA, Betts DH and Barcroft LC (1999) Gene expression regulating blastocyst formation Theriogenology $\mathbf{5 1}$ 117-133

Wu H, He CL, Jehn B, Black SJ and Fissore RA (1998) Partial characterization of the calcium-releasing activity of porcine sperm cytosolic extracts Developmental Biology 203 369-381

Received 10 March 2003.

First decision 30 June 2003.

Revised manuscript received 23 July 2003.

Accepted 6 August 2003. 